Recebido em 04/07/2018. Aprovado em 02/08/2018. Avaliado pelo sistema cabdeblindperrevien Publicado conforme normas da ABNT. http://dx.doi.org/10.22279/navus.2019.v9n1.p165-181.806

\title{
Logística reversa de pneus inservíveis: diagnóstico situacional com aplicação de matriz de indicadores de sustentabilidade nos municípios de Belém e Ananindeua, Pará
}

\author{
Paulo Vitor dos Santos Gonçalves Mestrando em Ciências Ambientais. Universidade do Estado do Pará (UEPA) - Brasil. santos-paulo@live.com \\ Paulo Amador Tavares Mestrando em Ciências Ambientais. Universidade do Estado do Pará (UEPA) - Brasil. \\ atavares.paulo@gmail.com \\ Norma Ely Santos Beltrão Doutora em Desenvolvimento Rural. Universidade do Estado do Pará (UEPA) - Brasil. \\ normaelybeltrao@gmail.com \\ Hélio Raymundo Ferreira Filho Doutor em Ciências de Gestão. Universidade do Estado do Pará (UEPA) - Brasil. helio.ferreira@uepba.br
}

\section{RESUMO}

No estado do Pará, os municípios de Belém e Ananindeua destacam-se pela elevada concentração de veículos e consequentemente pela quantidade de pneus inservíveis produzidos. 0 presente artigo teve por objetivo elaborar o diagnóstico situacional do cenário da logística reversa de pneus inservíveis nos municípios de Belém-PA e Ananindeua-PA e aplicar uma matriz Pressão-Estado-Impacto-Resposta (PEIR). A metodologia foi desenvolvida através de entrevistas não estruturadas com os principais elos responsáveis pela logística reversa nos municípios estudados, dentre eles: revended ores de pneus, borracharias e secretarias municipais de meio ambiente. Identificouse a ocorrência de pressões sobre o meio ambiente na área de estudo por causa dos pneus inservíveis. Foram identificados impactos, como enchentes, poluição do ar, água e solo, além de redução de matéria-prima proveniente de logística reversa. 0 estudo identificou duas situações distintas para os municípios em estudo quanto ao cenário da logística reversa dos pneus inservíveis. No primeiro, Ananindeua, verificou-se a presença do sistema de gestão dos resíduos de pneus que recebe e faz a coleta dos pneus inservíveis e permite ao consumidor final que destine corretamente o pneu usado no Ecoponto presente no município. No segundo, Belém, a resposta do poder público foi considerada como ineficiente, pois não existe um Ecoponto para coleta de pneus inservíveis no município. Conclui-se que a metodologia PEIR elaborou respostas para a gestão municipal com potencial para alterar o quadro de impactos ambientais causados pela coleta, disposição e tratamento irregular dos pneus inservíveis, assim como formas de aperfeiçoar o processo da logística reversa dos pneus usados.

Palavras-chave: PEIR. Política Ambiental. Resíduos Sólidos.

\section{Reverse logistic of unusable tires: situational diagnosis with application of framework of sustainability indicators for Belém and Ananindeua, Pará}

\begin{abstract}
In the state of Pará, the municipalities of Belém and Ananindeua stand out due to the high concentration of vehicles and consequently the large number of unusable tires produced. This paper aimed to elaborate a situational diagnosis of the reverse logistics of the unusable tire industry in the municipalities of Belém-PA and Ananindeua-PA applying the Pressure-State-Impact-Response (PSIR) framework. The methodology was developed through unstructured interviews with the main agents responsible for reverse logistics in both cities studied, among them: tire dealers, tire repair shops and municipal environmental agencies. Impacts, such as flooding, air and water pollution and soil contamination were identified, as well as the reduction of raw material that comes from reverse logistics. The study identified two distinct conditions for the municipalities of Ananindeua and Belém regarding the scenario of the reverse logistics of unusable tires. In the first one, Ananindeua, there is a management system for the unusable tires that receives and collects these tires, which allows the final consumers to dispense their unusable tires appropriately in an Ecoponto (Eco-point) which exists within the municipality area. In the second, Belém, the response of the public services was considered inefficient, as there is no Ecopontofor the collection of unusable tires in the municipality. We concluded that the PSIR methodology has elaborated responses to the municipal management with the potential to alter the environmental impact caused by the collection, disposal and irregular treatment of unusable tires, as well as ways to improve the reverse logistics process of unusable tires.
\end{abstract}

Keywords: PSIR. National Policy. Solid Waste. 


\section{INTRODUÇÃO}

Com a crescente preocupação com a proteção do meio ambiente e a elevada produção industrial de pneumáticos, a problemática da disposição inadequada dos resíduos de pneus aumentou principalmente por conta de suas características de difícil degradabilidade e por ocuparem muito espaço nos aterros sanitários (DHOUIB, 2014).

A questão ambiental da disposição inadequada desse resíduo é relevante também, quando se observa os valores de produção de novos pneus no Brasil no ano de 2016, em que foram inseridos cerca de 67,8 milhões de unidades de pneus, atingindo a marca de 694,5 milhões de unidades produzidas no período de 2006 a 2016 (ANIP, 2017). Atrelado aos números de produção, estima-se que 100 milhões de pneus estejam abandonados em aterros, lixões, córregos, lagoas e rios do Brasil, acarretando impactos ambientais, sérios problemas de saúde pública e gestão de resíduos (ANIP, 2017).

Os danos provocados ao meio ambiente por produtos descartados incorretamente fizeram com que a sociedade exigisse dos órgãos reguladores, formas de controle, redução e reversão dos impactos. Com isso, surgiram as legislações ambientais e regulamentações voltadas para a destinação adequada dos produtos usados (IBÁÑ̃ZZ-FÓRES et al., 2018).

Dentre as legislações, destaca-se a promulgação da Resolução no 416, de 30 de setembro de 2009, do Conselho Nacional do Meio Ambiente - CONAMA, que dispõe sobre a prevenção à degradação ambiental causada por pneus inservíveis e a sua destinação ambientalmente adequada, e dá outras providências.

A Política Nacional de Resíduos Sólidos - PNRS, instituída pela Lei 12.305 de 02 de agosto de 2010, também é uma importante ferramenta para atenuar os danos ambientais causados pelos pneus. Esta lei estabelece que todos os fabricantes, importadores, revended ores e comerciantes de pneus, e outros materiais, sejam responsáveis pela estruturação e implantação do sistema de logística reversa, retornando os produtos após o uso pelo consumidor para destinação adequada, de maneira independente do serviço público de limpeza urbana e de manejo dos resíduos sólidos.

Apesar dos avanços a respeito desta temática e do desenvolvimento da legislação e medidas mitigadoras, percebe-se que existem disparidades quanto ao volume de pneus inservíveis destinados de maneira adequada nas regiões do Brasil. No relatório de pneumáticos do Instituto Brasileiro do Meio Ambiente e dos Recursos Naturais Renováveis - IBAMA, do ano de 2016, foram destinadas cerca de 493 mil toneladas de pneus no Brasil, sendo o maior montante referente a região sudeste, com $50 \%$ de participação, e a menor participação advinda da região norte com 1,94\%, sendo nesta região, o Estado do Pará o menor contribuinte nacional com apenas 282 toneladas (0,06\% do total destinado) (IBAMA, 2017).

No Estado do Pará, de acordo com dados do IBGE (2017), Belém e Ananindeua são os municípios mais populosos e concentram uma frota aproximada de 572 mil veículos em geral (DENATRAN, 2018). A quantidade de veículos demonstra um cenário preocupante quanto à problemática de pneus inservíveis, visto que a contribuição da região para destinação adequada é reduzida quando comparada com outros estados e regiões do país.

Desta forma, percebe-se que existem pressões ambientais relacionadas à presença dos pneus inservíveis oriundos de uma quantidade elevada de veículos nesses municípios que podem gerar impacto ambiental. Assim, justifica-se a análise destas pressões e impactos causados por esses pneus como ferramenta para conhecer o cenário atual da interação desse tipo de resíduo com o meio ambiente e a sociedade nesses municípios. Portanto, o objetivo desta pesquisa é elaborar um diagnóstico situacional da logística reversa dos pneus inservíveis nos municípios de Belém-PA e Ananindeua-PA, através da aplicação do sistema de indicador de sustentabilidade pressão-estado-impacto-resposta (PEIR). 


\section{REVISÃO DE LITERATURA}

Para elucidar a temática em estudo, serão abordados aspectos sobre a legislação vigente no Brasil que contempla a destinação correta de pneus inservíveis, assim como conceitos fundamentais para a compreensão da logística reversa e do sistema indicadores de sustentabilidade.

Estes tópicos são fundamentais para a elaboração de um diagnóstico situacional da logística reversa de pneus inservíveis, uma vez que o dignóstico tem como objetivo revelar e garimpar informações que permitam conhecer o cenário em estudo (RODRIGUES; AOKI; OLIVER, 2015). 0 diagnóstico situacional é caracterizado como o resultado de um processo de coleta, tratamento e análise de dados colhidos no local onde deseja-se realizá-lo, sendo considerado uma importante ferramenta de gestão (SILVA; KOOPMANS; DAHER, 2016).

\subsection{Política Nacional dos Resíduos Sólidos}

Foram necessários 21 anos de discussões no Congresso Nacional para que o Governo Federal aprovasse e sancionasse a Política Nacional de Resíduos Sólidos - PNRS (GODOY, 2013). A Lei no 12.305 instituiu a PNRS, estabelecendo um quadro regulatório contendo elementos necessários para o setor de resíduos sólidos, buscando solucionar um dos grandes desafios enfrentados pelos governos e pelo conjunto da sociedade brasileira: a amplitude do problema da geração de resíduos sólidos e o seu manejo adequado (GOBBI et al., 2017).

A Lei no $12.305 / 10$ possui como principais pontos de inovação a inserção do conceito de responsabilidade compartilhada pelo ciclo de vida do produto, reconhecendo a necessidade de participação de todos os elos da cadeia, o incentivo ao desenvolvimento de cooperativas ou de outras formas de associação de catadores configurando uma ação socioambiental (BRASIL, 2010).

A logística reversa na PNRS é considerada um destes instrumentos de implementação da responsabilidade compartilhada, viabilizando um conjunto de ações que visam a coleta e a restituição dos produtos e resíduos sólidos remanescentes ao setor empresarial, para reaproveitamento em seu ciclo ou em outros ciclos produtivos, ou outra destinação final ambientalmente adequada (ABRELPE, 2015).

Com o conceito de logística reversa e responsabilidade compartilhada, a Lei $n=12.305 / 10$ no artigo 33 determina a obrigatoriedade dos fabricantes, importadores, distribuidores e comerciantes de pneus na implantação de um sistema de logística reversa, mediante o retorno dos produtos após o uso pelo consumidor, de forma independente do serviço público de limpeza urbana e de manejo de resíduos sólidos.

\subsection{Marco Regulatório para a Destinação Final de Pneus}

A preocupação em regulamentar os processos de destinação final de pneus ou pneumáticos é relativamente recente, e vem sendo liderada principalmente pelas ações do Conselho Nacional do Meio Ambiente - CONAMA, órgão do governo federal responsável pelas Resoluções, Moções e Recomendações destinadas a regulamentar algumas atividades ambientais mantidas pelas empresas (FLORIANI; FURLANETTO; SEHNEM, 2016).

A Resolução CONAMA № 258 de 26 de agosto de 1999, determina que os fabricantes sejam os responsáveis pelo destino dos pneus inservíveis. A resolução estabelece, desde 2002, que os fabricantes e importadores de pneus devem coletar e dar destinação final aos pneus inservíveis. A Resolução CONAMA no 258/99 entrou em revisão em 2006 pelo IBAMA, e em 30 de setembro de 2009, foi aprovada a Resolução CONAMA no 416/09 que dispõe sobre prevenção da degradação ambiental causada por pneus inservíveis e sobre a destinação final adequada a esses objetos (CONAMA, 1999; CONAMA, 2009).

A Resolução CONAMA no 416/09 classifica os pneus em novos, usados, reformados e inservíveis, e estabelece como destinação ambientalmente adequada os procedimentos em que os pneus são 
descaracterizados de sua forma inicial, e seus elementos constituintes reaproveitados, reciclados ou processados por técnicas admitidas pelos órgãos ambientais (CONAMA, 2009).

De acordo com Resolução CONAMA no 416/09, os fabricantes e importadores de pneus novos com peso unitário superior a $2 \mathrm{~kg}$, são obrigados a coletar e a proporcionar destinação final de seus resíduos ao final de sua vida útil. Além disso, é fixada uma meta em que para cada pneu comercializado para reposição, as empresas fabricantes ou importadoras deverão dar destinação adequada a um pneu inservível (CONAMA, 2009).

A Resolução recomenda ainda que, fabricantes e importadores devem elaborar um plano de gerenciamento de coleta, armazenamento e destinação de pneus inservíveis, com descrição da estratégia adotada para coleta, indicação de pontos de coleta para receber e armazenar provisoriamente os pneus e centrais de depósito para armazenamento temporário de pneus inservíveis, inteiros ou picados, descrição das modalidades de destinação, e programas educativos a serem desenvolvidos junto aos agentes envolvidos (LAGARINHOS; TENÓRIO, 2013).

Esta mesma resolução regulamenta que os fabricantes e importadores devem implantar pontos de coletas nos municípios com mais de 100.000 habitantes, ou terceirizar esse serviço desde que defina no seu plano de gerenciamento. Ainda prevê que os estabelecimentos de comercialização podem funcionar como pontos de coleta e que os fabricantes e importadores devem divulgar amplamente a localização dos pontos de coleta e das centrais de armazenamento de pneus inservíveis (CONAMA, 2009).

\subsection{Logística Reversa}

0 interesse dos gestores pela prática da logística reversa é crescente devido a vários fatores como 0 endurecimento das legislações ambientais, a pressão dos consumidores e os benefícios para a imagem da empresa (DEMAJ OROVIC; AUGUSTO; SOUZA, 2016). 0 autor ainda destaca que a competitividade e os avanços tecnológicos que propiciam, de um lado, a obsolescência dos produtos e diminuição do ciclo de vida, e de outro, o desenvolvimento de novos materiais e técnicas que possibilitam as atividades de reuso e reciclagem favorecendo a inserção da logística reversa nos processos de gestão.

A logística reversa, de acordo com Rogers e Tibben-Lembke (1998) é o processo de planejar, implementar e controlar os fluxos reversos de matérias-primas, em inventário de processo, embalagens e produtos acabados, desde o ponto de fabricação, distribuição ou uso, até um ponto de recuperação ou ponto de descarte adequado.

A Reverse Logistics Executive Council - RLEC, órgão de referência mundial sobre o assunto, também define a logística reversa como sendo o processo de movimentação de mercadorias do seu destino típico para outro ponto, com o objetivo de obter valor de outra maneira indisponível, ou com o objetivo de efetuar a disposição final dos produtos (RLEC, 2017).

Leite (2017) afirma que a Logística Reversa é a área da logística empresarial que projeta, atua e controla o fluxo e as informações logísticas adequadas ao retomo dos bens de pós-vendas e de pós-consumo ao ciclo de negócios ou ao ciclo produtivo, através dos canais de distribuição reversos, acrescentando-lhes valores econômicos, ecológicos, legais, logísticos, de imagem corporativa, entre outros.

De acordo com a PNRS (BRASIL, 2010), a logística reversa é considerada como instrumento de desenvolvimento econômico e social, caracterizado por um conjunto de ações, procedimentos e meios destinados a viabilizar a coleta e a restituição dos resíduo s sólidos ao setor empresarial, para reap roveitamento, em seu ciclo ou em outros ciclos produtivos, ou outra destinação final ambientalmente adequada.

Conforme Fonseca et al. (2017), as definições, de maneira geral, caracterizam a logística reversa como um conjunto de atividades de planejamento, controle e decisões voltadas ao fluxo de bens, resíduos, materiais ou peças, a montante das redes de suprimentos, ou seja, do consumidor ao produtor, com objetivos de revalorizar, ampliar os ciclos de vida e reduzir os descartes, ou destinar corretamente. 


\subsection{Logística Reversa de Pneus Inservíveis no Brasil}

Pedram et al. (2017), consideram o sistema de logística reversa um importante instrumento voltado à mitigação da problemática do pneu inservível, visto que sua correta implantação propicia a redução deste resíduo por meio da coleta, transporte e destinação ambientalmente adequada deste material.

Segundo Lagarinhos e Tenório (2013), a maior dificuldade para a implantação da logística reversa no Brasil é a realização da coleta e do transporte, pois em muitos casos, esses pneus estão localizados em regiões de difícil acesso, o que torna o processo inviável do ponto de vista econômico pelo custo logístico. Souza e D'Agosto (2013), ressaltam que o custo logístico representa cerca de dois terços do custo total do pneu processado, e corroboram a importância da elaboração de estudos sobre a configuração da rede logística reversa para a redução de tais custos.

A logística reversa de pneus inservíveis no Brasil tem como pioneira a Associação Nacional da Industria de Pneus - ANIP, que iniciou em 1999 o "Programa Nacional de Coleta e Destinação de Pneus Inservíveis", dando os primeiros passos para a gestão deste tipo de resíduo. Posteriormente, originou-se a partir deste programa a RECICLANIP, uma entidade sem fins lucrativos criada em 2007 pelos fabricantes de pneus com o objetivo de administrar o processo de coleta e destinação de pneus inservíveis em todas as regiões brasileiras (RECICLANIP, 2017).

A forma mais comum de destinação dos pneus inservíveis no Brasil é como combustível alternativo para a indústria de cimento, que em 2017 respondeu por 60,23\% do total. Em segundo lugar no ranking está a fabricação de granulado e pó de borracha para utilização em artefatos de borracha, ou asfalto borracha, respondendo por $27,15 \%$ da destinação. Na sequência, está a laminação, que utiliza o pneu inservível como matéria-prima para fabricar solado de sapato, dutos fluviais etc., que representam 11,54\%, e por fim, 0 uso no processo de pirólise com 1,08\% (IBAMA, 2017).

Assim, devido ao sucesso das ações da Reciclanip e principalmente devido a entrada em vigor da PNRS em 2010, nos últimos anos aumentou o enfoque quanto à situação dos pneus inservíveis nos Planos de Gestão Integrada de Resíduos Sólidos (PGIRS) dos principais municípios e capitais brasileiras, com parcerias e medidas concretas no sentido de viabilizar a coleta e a destinação ambientalmente adequada desse passivo ambiental no território nacional (FLORIANI; FURLANETTO; SEHNEM, 2016).

\subsection{Sistema Indicador de Sustentabilidade}

Os sistemas indicadores de sustentabilidade são importantes instrumentos de mensuração utilizados para prover informações para o desenvolvimento sustentável do meio ambiente, da economia e da sociedade (VERMA; RAGHUBANSHI, 2018). Esses indicadores são ferramentas que auxiliam os tomadores de decisão na avaliação de desempenho em relação aos objetivos estabelecidos com informações para o planejamento de futuras ações (PUPPHACHAl; ZUIDEMA, 2017).

0 uso do sistema de indicadores contribui para a análise dos impactos que incidem sobre o meio ambiente e a redução ou mitigação dos mesmos, e sintetizam as informações sobre os fenômenos estudados de forma a facilitar no processo de comunicação com os diferentes públicos-alvo (RAMOS-QUINTANA et al., 2018). A análise dos indicadores reflete na percepção dos atores envolvidos na pesquisa, considera os fatores do lugar estudado e permite o entendimento da complexidade inerente a cada localidade (LIU et al., 2018).

Além disso, os indicadores de sustentabilidade constituem parâmetros com relevante enfoque sobre a realidade em escalas diferentes de abrangência, dentro de um contexto multidisciplinar, para suprir com informações contundentes na tomada de decisão (EHARA et al., 2018). Assim, devido a utilidade deste instrumento, cresce a busca pela sua elaboração por parte dos organismos governamentais, não governamentais, institutos de pesquisa e universidades em todo o mundo (PUPPHAICHAl; ZUIDEMA, 2017). 


\section{METODOLOGIA}

Neste capítulo é caracterizada a pesquisa, a área de estudo e a coleta de dados.

\subsection{Caracterização da Pesquisa}

Do ponto de vista de sua natureza esta pesquisa é caracterizada como aplicada, pois, busca gerar conhecimento para aplicação prática e apresenta caráter exploratório quanto aos objetivos, que permite 0 estudo do tema sob diversos ângulos e aspectos com o intuito de proporcionar mais informações sobre 0 assunto investigado, possibilitando sua definição e seu delineamento. Quanto aos procedimentos é caracterizada como pesquisa bibliográfica, uma vez que é elaborada a partir de material já publicado, e como levantamento (survey), pois envolve também a interrogação dos indivíduos cujo comportamento deseja-se conhecer por meio de questionários (PRODANOV; FREITAS, 2013).

\section{2 Área de Estudo}

O município de Belém, localizado no estado do Pará, de acordo com o IBGE (2017), apresenta uma população de 1.452.275 de habitantes, distribuídos em uma área de 1.059,402 km², com uma densidade demográfica de 1,3 habitantes/ $/ \mathrm{km}^{2}$ (IBGE, 2010). 0 município de Belém está distribuído em oito distritos administrativos e 71 bairros. 0 município de Belém apresenta cerca de 227 mil automóveis em uma frota total de aproximadamente 440 mil veículos em geral (DENATRAN, 2018).

Enquanto que o município de Ananindeua, localizado também no estado do Pará, apresenta uma população de 516.057 habitantes (IBGE, 2017), com uma área municipal de 190,451km² e uma densidade demográfica de 2,4 habitantes/ $/ \mathrm{km}^{2}$ (IBGE, 2010). 0 município de Ananindeua está distribuído em 26 bairros incluindo área rural e 14 ilhas. 0 município de Ananindeua apresenta por volta de 62 mil automóveis em uma frota total de aproximadamente 131 mil veículos em geral (DENATRAN, 2018).

Os municípios de Belém e Ananindeua, integrantes da Região Metropolitana de Belém, apresentam a maior frota de veículos registradas no levantamento bibliográfico, gerando um maior índice de pneus inservíveis, que justifica a escolha destes como área de estudo. A Figura 2 apresenta o mapa de localização das áreas utilizadas para a realização da pesquisa.

Figura 2 - Localização dos municípios de Belém e Ananindeua, no estado do Pará
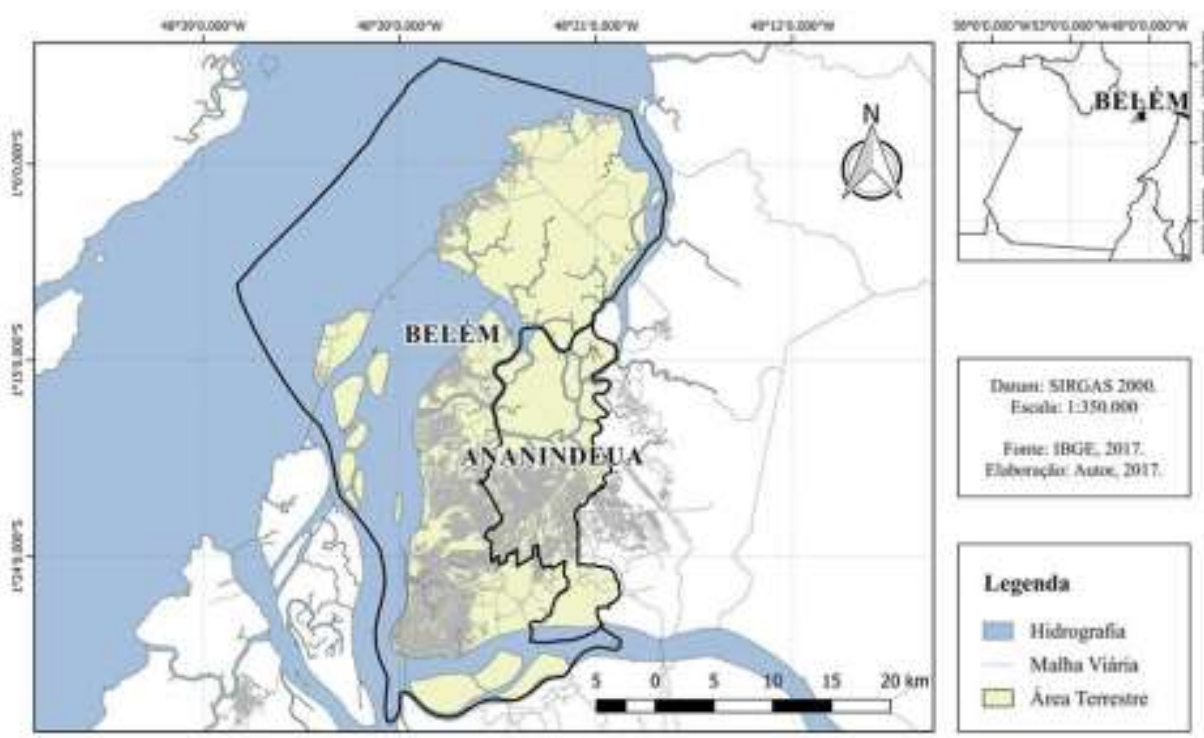

Fonte: IBGE (2017). 


\subsection{Coleta de Dados}

A fase de coleta de dados iniciou no levantamento dos dados secundários existentes sobre o assunto nas instituições que atuam no setor por meio de pesquisa bibliográfica. Posteriormente, foi realizado levantamento dos principais atores envolvidos no sistema de logística reversa dos pneumáticos nos municípios de Belém-Pa e Ananindeua-PA: borracharias, pontos da RECICLANIP revendedores e demais distribuidores e nos representantes do poder público de Belém e Ananindeua que são as Secretarias Municipais de Meio Ambiente - SEMMA.

Devido a inexistência de dados sobre a quantidade de empresas do segmento de pneus e borracharias nos municípios de Belém e Ananindeua e a distância de um estabelecimento para outro, foi utilizado como espaço amostral as seis revendedoras de pneus autorizadas presentes na área de estudo que estão associadas à Reciclanip, sendo quatro localizadas no município de Belém e duas em Ananindeua, cinco borracharias em diferentes bairros e as secretarias municipais de meio ambiente dos municípios de Belém e Ananindeua.

Os formulários foram elaborados de acordo com a bibliografia (GOVINDAN; BOUZON, 2018), e abordam aspectos relativos às dificuldades, às iniciativas e à destinação dos pneus inservíveis pelos revendedores, consumidores e poder público, nível de conhecimento quanto ao tema e sobre o armazenamento, transporte e coleta dos pneus inservíveis, de forma que subsidiem informações para elaboração do cenário da logística reversa na área de estudo.

\subsection{Análise de Dados}

A análise de dados foi baseada em formulários e na matriz PEIR, apresentados nas seções seguintes.

\subsubsection{Formulários}

Os dados coletados obtidos pelos formulários aplicados foram discutidos de acordo com a legislação ambiental aplicada e a pesquisa bibliográfica relacionado aos pneus inservíveis e a logística reversa. Os formulários permitiram o levantamento (survey) qualitativo dos principais elos responsáveis pela logística reversa na área de estudo com informações relevantes e que serviram como fundamento para a elaboração do sistema indicador de sustentabilidade por meio da matriz PEIR.

\subsubsection{Matriz PEIR}

Utilizou-se a metodologia Pressão-Estado-Impacto-Resposta (PEIR), um modelo adaptado do Programa das Nações Unidas e Meio Ambiente - PNUMA (2001) que o define como a resultância entre as pressões ocasionadas pelas atividades humanas e o meio ambiente e implica na identificação das atividades antrópicas que afetam o meio ambiente (SILVA et al., 2012).

A matriz PEIR é considerada um instrumento analítico que organiza e agrupa de maneira lógica os fatores que atingem o meio ambiente, os efeitos que as ações humanas produzem nos ecossistemas e recursos naturais, o impacto que isto gera na natureza e na saúde humana, assim como as interven ções da sociedade e do poder público (LEWISON et al., 2016). A Figura 3 ilustra o modelo da matriz PEIR utilizada para a elaboração dos indicadores de sustentabilidade. 
Figura 3 - Fluxograma de interação dos componentes da matriz PEIR

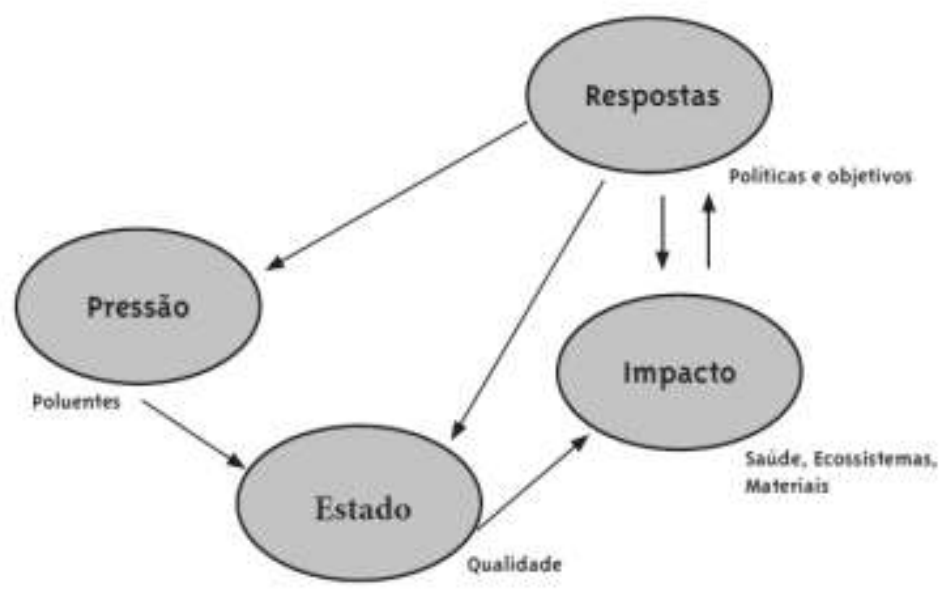

Fonte: Adaptado de Lima et al. (2017).

Neste modelo, o item "pressão" buscou responder os fatores resultados da atividade humana que incidem sobre o meio ambiente e que produzem mudanças ambientais. $O$ item "estado" considerou a condição ou qualidade do meio ambiente que resulta das pressões. 0 item "impacto" referiu-se ao efeito do estado ou condição do meio ambiente sobre diferentes aspectos, como os ecossistemas, a qualidade de vida humana, a economia local. E o item "resposta" foi o elemento da matriz que considerou as ações desenvolvidas com o objetivo de prevenir impactos ambientais negativos, corrigir os danos ao meio ambiente ou conservar os recursos naturais (PNUMA, 2001; GUIMARÃES et al., 2010).

\section{RESULTADOS E DISCUSSÕES} anteriormente.

Este capítulo apresenta os resultados da pesquisa, levando em conta a metodologia apresentada

\subsection{Cenário da Logística Reversa na Área de Estudo}

O cenário e os resultados obtidos na área de estudo são apresentados nesta seção.

\subsubsection{Poder Público}

No município de Belém, em entrevista com a SEMMA local, foi verificada a ausência de um sistema estruturado de coleta de pneus inservíveis junto às entidades envolvidas (revendedoras e borracharias) e de um ponto de coleta, intitulado de Ecoponto, conforme é determinado pela Resolução CONAMA no 416/09, demonstrando precariedade e ineficiência do processo.

A inexistência de um Ecoponto inviabiliza para o consumidor final e para as entidades envolvidas a destinação do pneu inservível e permite que os resíduos de pneus gerados sejam dispostos nos aterros por meio da coleta regular ou de forma irregular em áreas impróprias, acrescentando problemas ambientais. Speranza e Moretti (2014), em um estudo de caso de análise dos processos de logística reversa da cadeia de pneus inservíveis, aponta que esses Ecopontos possibilitam a entrega do consumidor final, de forma a reduzir os custos operacionais de coleta e que a participação do poder público é fundamental para o auxílio na coleta, transporte e armazenamento dos pneus nestes estabelecimentos, contribuindo com o sistema da Reciclanip.

No município de Ananindeua, a entrevista com a SEMMA deste município permitiu a constatação da existência de um sistema de armazenamento de pneus inservíveis e a presença de uma estrutura de coleta nas 
revendedoras e borracharias através de caminhão. Os pneus são coletados e transportados para um Ecoponto para serem armazenados em local adequado e, posteriormente, são recolhidos pela Reciclanip e direcionados para outros locais, fora do estado para serem reciclados.

O sistema implementado em Ananindeua viabiliza que o consumidor final destine o pneu diretamente no órgão público, onde é emitido um documento que comprova a ação. É importante destacar que este sistema engloba todos os atores, principalmente as borracharias, maximizando a quantidade de resíduos recuperados e minimizando os problemas ambientais.

\subsubsection{Revendedoras de Pneus}

As revendedoras associadas a Reciclanip afirmam que a responsabilidade de coletar os pneus inservíveis parte dos fabricantes de acordo com $83 \%$ dos entrevistados. Para $50 \%$ dessas pessoas, isso ocorre por meio de iniciativas pautadas em uma fundamentação ecológica, pois reflete na imagem corporativa da empresa devido a responsabilidade com a sociedade e o meio ambiente. Para Luz e Durante (2013), essa iniciativa de destinar adequadamente os pneus inservíveis tornou-se essencial para o desenvolvimento sustentável do país, mesmo com elevados custos de execução e manutenção, visto que os pneus inservíveis representam um passivo ambiental que necessita de solução, para evitar problemas sociais, ambientais e de saúde pública.

Quanto ao recolhimento dos pneus no local de armazenamento e destinação, as 4 revendedoras localizadas no município de Belém afirmam que este procedimento é feito de maneira autônoma, enquanto que as 2 representantes localizadas no município de Ananindeua são atendidas pelo sistema de coleta de pneus inservíveis do Poder Público.

Em contrapartida, o nível de conhecimento quanto ao destino final destes pneus inservíveis recolhidos é em $83 \%$ dos resultados médio e baixo, demonstrando fragilidade nas informações sobre o sistema logístico reverso. Para a ANIP (2017), a implantação do sistema de logística reversa dos pneus inservíveis no Brasil envolve a participação de vários colaboradores, dos quais estão envolvidos os distribuidores, revendedores, reformadores e consertadores, incluindo também os consumidores finais, em articulação com os fabricantes, importadores e o Poder Público, de forma a contemplar o princípio de responsabilidade compartilhada presente na Lei $\mathrm{n} 012.305$ de 2010.

A fiscalização nas revendedoras quanto o cumprimento da Resolução CONAMA № 416/09 nunca foi realizada em $50 \%$ dos entrevistad os, enquanto que $17 \%$ afirmaram que raramente há fiscalização, visando seu cumprimento. Couto e Lange (2017), ao estudarem os sistemas de logística reversa no Brasil, destacaram a necessidade do envolvimento do poder público municipal no gerenciamento adequado dos pneus inservíveis para o cumprimento da Resolução CONAMA 416/09 e para o cumprimento do que é regulamentado pela PNRS, pois a fiscalização adequada poderá manter um ritmo satisfatório nas atividades de coleta e destinação de pneus inservíveis e assim alcançar os objetivos revistos na regulamentação, acrescentando positivamente na proteção do meio ambiente e saúde pública.

0 percentual de retorno dos pneus inservíveis é em $67 \%$ das revendedoras pesquisadas considerado insuficiente, pois quase não há destinação por conta da contribuição do consumidor final, variando de 0 a $25 \%$ dos usuários que deixam o pneu inservível nestas revendedoras para seguimento da logística reversa desse resíduo. Esse baixo índice de retorno dos pneus por parte dos consumidores pode ser agravado pelo fato de não haver, em $83 \%$ das revendedoras entrevistadas, estratégias para incentivar este consumidor final a contribuir, destinando o pneu inservível no momento da troca por um novo.

Esse retorno insuficiente de pneus reflete na conscientização dos consumidores finais, que quando não destinam às revendedoras os pneus inservíveis, promovem a disposição irregular ou em aterros, que é considerada inviável pois este resíduo apresenta baixa compressibilidade, não sofre biodegradação e ocupa muito espaço (LAGARINHOS, 2011). Moreira e Guarnieri (2016), em um estudo sobre a responsabilidade ambiental dos consumidores com embalagens de produtos, afirmam que a conscientização destes consumidores agrega valor nas estratégias de logística reversa, assim como fideliza este consumidor à empresa que adota medidas de retorno dos resíduos. 


\subsubsection{Borracharias}

A pesquisa nas borracharias se concentrou no município de Belém, uma vez que Ananindeua apresenta uma rede estruturada para coleta de pneus inservíveis junto aos borracheiros da região. Partindo desta premissa, as borracharias pesquisadas apontaram em $80 \%$ dos resultados, não possuir conhecimento sobre a destinação correta dos pneus inservíveis. Conforme Luz e Durante (2013) apontam, a falta de informação reflete na ineficiência da logística reversa e resulta na baixa eficiência de processamento em função do não atingimento dos volumes mínimos.

As borracharias, em $100 \%$ dos resultados, enfatizaram que o poder público não realiza a coleta adequada dos pneus inservíveis, ressaltando a precariedade do cenário no município de Belém quanto à gestão dos resíduos de pneus. Em $60 \%$ das borracharias pesquisadas, os pneus são acondicionados em local adequado e $40 \%$ não apresentam o armazenamento correto, o que contribui para problemas ambientais e de saúde pública. Lagarinhos (2011) argumenta que esses depósitos de pneus inservíveis servem como criadouros de mosquitos devido às condições climáticas e serem propícios a retenção de água.

Das borracharias entrevistadas, $80 \%$ afirmam que a coleta irregular por carroceiros é tida como 0 principal meio de destino dos pneus inservíveis. Esse processo de coleta irregular, conforme destaca Lagarinhos (2011), permite o maior risco a disposição irregular, com acúmulo desses materiais em aterros, aumento do índice de enchentes provocadas por pneus abandonados em córregos, e o risco de incêndios, causando problemas à sociedade e para o meio ambiente.

Em 80\% das entrevistas, notou-se o desconhecimento sobre logística reversa de pneus inservíveis, que dificulta a realização do processo e evidencia a ausência de informações para que ocorra a viabilidade do processo. Leite (2017), considera que conhecer e incorporar a prática da logística reversa pode proporcionar benefícios ambientais e econômicos, reduzindo o volume de descarte, além de criar de novos negócios na cadeia produtiva. A falta de informação sobre logística reversa pode ser considerado um empecilho para a articulação da PNRS, Lei no 12.305/10, que apresenta em seu escopo a LR e a responsabilidade compartilhada como instrumentos de gestão dos resíduos sólidos.

\subsection{Matriz PEIR}

O Quadro 1 apresenta os principais indicadores de sustentabilidade da Matriz PEIR, estabelecido de acordo com as proposições do modelo do elaborado pelo PNUMA. A matriz é resultado das informações adquiridas no diagnóstico da situação do cenário logístico reverso dos pneus inservíveis nos municípios de Belém e Ananindeua, no estado do Pará.

Quadro 1 - Indicadores de Sustentabilidade conforme Matriz PEIR

\begin{tabular}{|l|l|l|l|}
\hline \multicolumn{4}{|c|}{ Tema: Resíduos Sólidos de Pneus } \\
\hline \multicolumn{1}{|c|}{ Pressão } & \multicolumn{2}{|c|}{ Estado } & \multicolumn{1}{c|}{ Impacto } \\
$\begin{array}{l}\text { P1. Aumento da } \\
\text { Frota de veículos }\end{array}$ & $\begin{array}{l}\text { E1. Qualidade } \\
\text { da água }\end{array}$ & I1. Enchentes & $\begin{array}{l}\text { R1. Elaboração de plano } \\
\text { municipal de gestão de } \\
\text { resíduos de pneus }\end{array}$ \\
\hline $\begin{array}{l}\text { P2. Aumento do } \\
\text { volume de resíduos } \\
\text { de pneus gerados }\end{array}$ & $\begin{array}{l}\text { E2. Qualidade } \\
\text { do solo }\end{array}$ & $\begin{array}{l}\text { I2. Impacto } \\
\text { sobre a saúde } \\
\text { humana }\end{array}$ & $\begin{array}{l}\text { R2. Estabelecimento de sistema } \\
\text { de coleta e Ecoponto em } \\
\text { articulação com os atores deste } \\
\text { setor }\end{array}$ \\
\hline
\end{tabular}




\begin{tabular}{|c|c|c|c|}
\hline $\begin{array}{l}\text { P3. Coleta irregular } \\
\text { dos resíduos de } \\
\text { pneus }\end{array}$ & $\begin{array}{l}\text { E3. Qualidade } \\
\text { do ar }\end{array}$ & $\begin{array}{l}\text { I3. Poluição } \\
\text { hídrica }\end{array}$ & $\begin{array}{l}\text { R3. Atividades de educação } \\
\text { ambiental para potencializar a } \\
\text { contribuição da comunidade }\end{array}$ \\
\hline \begin{tabular}{|lr} 
P4. & Disposição \\
irregular & dos \\
resíduos de pneus
\end{tabular} & \begin{tabular}{|l} 
E4. \\
Favorabilidade \\
a proliferação \\
de vetores de \\
doenças
\end{tabular} & $\begin{array}{l}\text { 14. Poluição do } \\
\text { solo }\end{array}$ & $\begin{array}{l}\text { R4. Capacitação dos entes } \\
\text { envolvidos no processo de } \\
\text { logística reversa de pneus } \\
\text { inservíveis }\end{array}$ \\
\hline $\begin{array}{l}\text { P5. Presença de } \\
\text { resíduos de pneus } \\
\text { em lixões e aterros }\end{array}$ & $\begin{array}{l}\text { E5. } \\
\text { Concentração } \\
\text { de resíduos de } \\
\text { pneus em áreas } \\
\text { inapropriadas }\end{array}$ & $\begin{array}{l}\text { 15. Poluição do } \\
\text { ar }\end{array}$ & $\begin{array}{l}\text { R5. Estudos de viabilidade de } \\
\text { reaproveitamento de pneus } \\
\text { inservíveis na região }\end{array}$ \\
\hline $\begin{array}{l}\text { P6. Contribuição } \\
\text { baixa de pneus } \\
\text { inservíveis para o } \\
\text { sistema de logística } \\
\text { reversa }\end{array}$ & & $\begin{array}{l}\text { 16. Redução da } \\
\text { matéria-prima } \\
\text { advinda da } \\
\text { reciclagem e } \\
\text { recuperação } \\
\text { do pneu } \\
\text { inservível }\end{array}$ & \\
\hline
\end{tabular}

Fonte: Autores (2018).

\subsubsection{Indicadores de Pressão}

De acordo com Malekmohammadi e Jahanishakib (2017), os indicadores de pressão estão relacionados às atividades humanas e a pressão que elas impõem sobre o meio ambiente através de suas atividades e processos. Foram identificados no estudo seis indicadores de Pressão como mostra a matriz presente no Quadro 1. Esses indicadores estão relacionados aos problemas causados pelos resíduos de pneus e a ausência de um sistema de coleta e destinação efetiva como identificado no diagnóstico do cenário da logística reversa do município de Belém.

O indicador de pressão P1, referente ao aumento da frota de veículos, por se tratar do modal de transporte mais utilizado no Brasil, por conta principalmente de sua capilaridade e flexibilidade (PERIM et al., 2017), incide diretamente na quantidade de pneus produzidos para abastecer esse mercado. A ANIP, em 2016, relatou que foram fabricad os cerca de 67,8 milhões de pneus no Brasil, com crescimento de 5 milhões de novas unidades de pneus em relação aos valores de produção do ano de 2012 (ANIP, 2016). Em consequência, há o aumento do volume de resíduos de pneus gerados, indicador de pressão P2, que são potencialmente perigosos devido ao risco ambiental associado ao descarte inadequado (BAUER, 2015).

Os indicadores de pressão, P3 e P4, abordam, respectivamente, a coleta e a disposição irregular dos pneus inservíveis. Para Faustino e Leite (2014), a não realização da coleta e o descarte irregular deste resíduo representam um grande passivo ambiental com necessidade de gerenciamento para evitar diversos danos ambientais e à saúde pública. Esses fatores de coleta e disposição irregular, como registrado no diagnóstico feito nos municípios, acarreta no indicador de pressão P5, que trata sobre a presença de resíduos de pneus em lixões e aterros. A disposição dos pneus inservíveis em aterros sanitários e lixões é proibida pela Resolução CONAMA $n$ ㅇ 416/09, por possuírem grandes dimensões, baixa compressibilidade, não serem biodegradáveis, além de servirem como logradouro para vetores de doenças quando expostos a céu aberto (CONAMA, 2009).

0 indicador de pressão $\mathrm{P} 6$, que faz menção à baixa contribuição de pneus inservíveis para o sistema de logística reversa, retrata o cenário atual do município de Belém, em que não há a gestão adequada dos pneus inservíveis pela prefeitura local junto aos entes envolvidos da cadeia logística. Para Bauer (2015), a 
logística reversa inclui na sua abordagem a redução na geração dos resíduos na fonte e a otimização dos canais de retorno, como a reciclagem, reaproveitamento e remanufatura, contribuindo para a problemática dos pneus inservíveis.

\subsubsection{Indicadores de Estado}

Os indicadores de Estado possuem a função de mostrar a situação em que determinado sistema se encontra, a partir da pressão exercida, descrevendo o efeito sobre o ambiente, a saúde humana e a sociedade (SCHNEIDER et al., 2010). A pesquisa identificou cinco indicadores de Estado, conforme exibido na matriz do Quadro 1, os quais fornecem uma visão do ambiente resultante das pressões relacionadas aos resíduos de pneus inservíveis.

A influência dos indicadores de Estado E1, E2 e E3, os quais abordam sobre a qualidade da água, do solo e do ar, respectivamente, é percebida no estudo de Bauer (2015), onde o autor afirma que a coleta e descarte inadequado dos pneus inservíveis, provoca danos ao meio ambiente, alterando seu estado, tais como: contaminação do solo, poluição do ar por emissão de gases tóxicos, além de permitir que este resíduo seja encontrado em corpos hídricos.

O município de Belém devido a não apresentar medidas de coleta e armazenamento dos pneus inservíveis tende a apresentar alterações no estado do meio ambiente resultante desse passivo ambiental, já que permite o seu descarte inadequado. 0 município de Ananindeua, por controlar o descarte dos pneus inservíveis com o sistema de coleta e armazenamento, reduz as pressões do dispêndio irregular dos pneus que resultam em alterações no estado do meio ambiente.

O indicador de Estado E4 concentra a questão da favorabilidade de proliferação de vetores de doenças. Fagundes, Amorim e Lima (2017), dizem que o descarte inadequado e o formato de tubo favorecem a retenção de água da chuva e absorção da luz do sol, fatores relevantes para a criação de um ambiente propício a proliferação de micro e macro vetores de diversas doenças. Corrêa, Costa e Pereira (2016), destacam que nos municípios de Belém e Ananindeua é comumente verificada a proliferação de doenças como a dengue, devido às condições climáticas. Assim, a disposição irregular dos pneus na área de estudo, propiciando logradouro aos vetores, intensifica o quadro natural de estado do meio ambiente.

$\mathrm{O}$ indicador de Estado E5, concentração de resíduos de pneus em áreas inapropriadas, promove a alteração do meio ambiente já discutida nos indicadores de estado anteriores, sendo, portanto, o indicador mais contundente deste grupo. 0 município de Belém apresenta o cenário mais preocupante quanto a concentração dos pneus inservíveis em área inadequadas, visto que o Poder Público do município não apresenta a prática da logística reversa com sistema de coleta e disposição regular dos pneus.

\subsubsection{Indicadores de Impacto}

Os indicadores de impacto identificam as consequências geradas por ações antrópicas e quanto elas estão afetando o meio ambiente, alterando e dando evidência ao estado no qual se encontra a comunidade e auxiliam que sejam evitados novos impactos no sistema (EHARA et al., 2018; LIU et al., 2018). 0 estudo conta com seis indicadores de Impacto, presentes na matriz do Quadro 1, elaborados a partir da análise do estado do meio ambiente em interação com os resíduos de pneus.

A ocorrência de enchentes, indicador de Impacto I1, para Hoornweg, Bhada-Tata e Kennedy (2013), está relacionado ao dispêndio irregular de pneus cujo contribui para o assoreamento dos corpos d'água e o entupimento de galerias fluviais, gerando, indiretamente, o transbordamento de rios e as enchentes nas grandes cidades, resultando no indicador de impacto 13 , poluição hídrica.

0 indicador de Impacto 12 , trata a questão dos impactos sobre a saúde humana, onde há um registro crescente de casos de doenças causadas pelo mosquito Aedes Aegypti devido em parte ao descarte incorreto de pneus inservíveis no meio ambiente, além disso, ocorre a incidência de outras doenças associadas a esta problemática como a malária e a proliferação de animais peçonhentos e roedores que utilizam os pneus como logradouro (FAGUNDES; AMORIM; LIMA, 2017). 
Para Luz e Durante (2013), a emissão dos gases tóxicos, que contaminam o ar, é associada ao processo de incineração dos pneus inservíveis, que ocorre maneira ilegal e por falta de um sistema de coleta e destinação adequada. Faustino e Leite (2014) destacam que o processo de incineração pode ocorrer de forma natural em lixões e aterros quando impropriamente armazenados, gerando um grande problema ambiental. A incineração provoca a liberação de óleos que contaminam os lençóis freáticos e o solo e produz gases tóxicos (LUZ; DURANTE, 2013), justificando a elaboração dos indicadores de Impacto I3, 14 e I5, referentes às poluições hídricas, do solo e do ar, respectivamente.

0 indicador de Impacto 16, que aborda a redução da matéria-prima advinda da reciclagem e recuperação de pneus inservíveis, é reflexo do cenário atual do município de Belém, que não apresenta um sistema implantado de coleta e disposição dos resíduos de pneus por meio da logística reversa. Para Dhouib (2014), o pneu inservível é considerado um passivo ambiental devido aos problemas ambientais relacionados a este resíduo, sendo determinado pela legislação, que seu armazenamento, no fim de sua vida útil, deve ser controlado e possuir uma destinação final para ser útil a outra cadeia produtiva por meio de alternativas de reciclagem.

\subsubsection{Indicadores de Resposta}

Os indicadores de Resposta são os componentes da metodologia PEIR que correspondem às ações coletivas ou individuais que aliviam ou previnem os impactos ambientais negativos, corrigem os danos ao meio ambiente, conservam os recursos naturais ou contribuem para melhorias da qualidade de vida da comunidade local (SARMIN et al., 2016). Foram elaborados cinco indicadores de Resposta, presentes na matriz do Quadro 1, de forma a propor medidas que atenuem os impactos relacionados aos resíduos de pneus inservíveis.

O primeiro indicador de Resposta R1, está relacionado a elaboração do plano municipal de gestão dos resíduos de pneus, que deve ter como foco o município de Belém, que apresenta uma gestão precária dos pneus inservíveis, necessitando de estudos para que se adequem às medidas estabelecidas tanto pela PNRS quanto pela Resolução CONAMA no 416/09, as quais determinam a participação do Poder Público na disposição adequada deste tipo de resíduo e a responsabilidade compartilhada com os principais agentes do setor de pneumáticos, uma vez que no âmbito municipal, a gestão dos pneus inservíveis é relevante para os diversos agentes.

O estabelecimento de sistema de coleta e do Ecoponto em articulação com os atores deste setor, indicador de Resposta R2, é essencial para a elaboração de um plano de gestão dos pneus inservíveis por meio da prática da logística reversa e é exigido pela Resolução CONAMA 416/09 a existência de pelo menos um Ecoponto para cidades com população de 100 mil habitantes ou superior. Bernardo e Lima (2017), ao estudarem o planejamento e implantação de programas de coleta seletiva, destacam que os Ecopontos servem como elo entre o consumidor final e as opções de tratamento disponível, onde o planejamento destes estabelecimentos otimiza a utilização de recursos e material humano.

De acordo com Reciclanip (2017), os Ecopontos devem funcionar em convênio com a Reciclanip e são centros de recepção de pneus usados, administrados e disponibilizados pelo Poder Público Municipal, para que sejam direcionados após o recolhimento pelo serviço de Limpeza Pública ou diretamente pelos consumidores e atores do setor de pneumáticos. 0 sistema de coleta e local para armazenamento (Ecoponto) é fundamental para a implantação da logística reversa no município de Belém, visto que Ananindeua apresenta a gestão estabelecida para os pneus inservíveis.

A prática de atividades de educação ambiental com a comunidade e a capacitação dos entes envolvidos na logística reversa dos pneus inservíveis, indicadores de Resposta R3 e R4, respectivamente, é imprescindível para o funcionamento do sistema logístico reverso dos resíduos de pneus. De acordo com o estudo realizado por Floriani, Furalanetto e Sehnem (2016), que abordou sobre o processo de coleta e descarte de pneus inservíveis no cenário nacional, a implementação de sistemas reversos para pneus passa pela necessária conscientização ambiental dos consumidores, revendedores e borracheiros sobre os impactos e a má gestão do passivo ambiental. 
A Resolução CONAMA no 416/09 preconiza a realização de programas educacionais junto aos entes envolvidos no processo de logística reversa dos pneus e consumidores, a fim de nortear as etapas que compreendem desde a coleta até a destinação final. A disseminação do conhecimento é relevante tanto para o sucesso do possível sistema de gestão de pneus inservíveis no munícipio de Belém, quanto para potencializar o sistema de retorno dos pneus estabelecido no município de Ananindeua.

Estudos de viabilidade de reaproveitamento de pneus inservíveis, indicador de Resposta R5, são necessários para mudar o quadro da baixa contribuição da região Norte no processo de reaproveitamento de pneus, desenvolvendo a região, gerando renda, assim como matéria-prima resultante do processo de reaproveitamento do pneu. Ademais, o reaproveitamento na região promoveria a desoneração do processo de destinação dos pneus inservíveis para o tratamento em outras regiões, configurado em fluxos intermunicipais de longas distâncias (BARTHLOMEU, 2010).

\section{CONCLUSÕES}

O estudo identificou os principais agentes ligados ao setor de pneumáticos nos municípios de Belém e Ananindeua e, por meio dos formulários aplicados, foi possível obter informações relevantes para a elaboração do cenário da logística reversa e de um sistema indicador de sustentabilidade PEIR.

A pesquisa caracterizou duas situações distintas nos municípios de Belém e Ananindeua. Foi verificado no município de Ananindeua a presença de um sistema de gestão dos resíduos de pneus em parceria com a Reciclanip, que recebe e faz a coleta dos pneus inservíveis nas revendedoras e borracharias, assim como permite ao consumidor final uma via de disposição do pneu usado no Ecoponto presente no município. Em contrapartida, o município de Belém, capital do Estado do Pará, apresenta um sistema precário de logística reversa de pneus em não conformidade com o estabelecido pela Resolução $n$ ㄴ416/09 e pela PNRS. Belém não apresenta sistema de coleta e o Ecoponto para a destinação adequada dos pneus, que inviabiliza a participação mais abrangente dos entes envolvidos no setor de pneumáticos e promove diversos impactos ambientais advindos da disposição irregular do pneu usado.

0 diagnóstico permitiu a elaboração de 22 indicadores de sustentabilidade de acordo com a metodologia da Matriz de indicadores PEIR. Esses indicadores auxiliaram na visualização do estado atual do meio ambiente, principalmente em Belém, que não apresenta medidas do Poder Público que mitiguem os danos causados pelo resíduo de pneu. Ademais, a metodologia PEIR elaborou respostas para a gestão municipal que alterem o quadro de impactos ambientais causados pela coleta, disposição e tratamento irregular dos pneus inservíveis, assim como formas de potencializar o processo da logística reversa dos pneus usados.

Desta forma, atingiu-se o objetivo do estudo, com a apresentação das atividades desenvolvidas nos municípios para realizar o processo de retorno dos pneus inseríveis e sua destinação adequada, assim como a elaboração do sistema de indicador de sustentabilidade PEIR.

É necessário destacar que o estudo apresentou limitações quanto a falta de registros oficiais da quantidade exata de revendedoras e borracharias na área de estudo para elaboração de um espaço amostral com erro amostral representativo. Por fim, sugere-se que sejam realizadas novas pesquisas abrangendo uma quantidade maior de atores, a fim de inferir o resultado amostral mais próximo da realidade da população estudada e, assim, construir um diagnóstico que colete mais informações sobre a logística reversa de pneus inservíveis nos municípios de Belém e Ananindeua-Pa.

\section{REFERÊNCIAS}

ABRELPE. Panorama dos resíduos sólidos no Brasil. Brasil: Grappa Editora e Comunicação, 2015. Disponível em: http://www.abrelpe.org.br/Panorama/panorama2015.pdf. Acesso em: 28 fev. 2017.

ANIP. Produção na indústria brasileira e reciclagem de pneus. [2017]. Disponível em: http://www.anip.com.br. Acesso em: 27 fev. 2017. 
BARTHOLOMEU, D. B.; BRANCO, J. E. H.; CAIXETA FILHO, J. V.; PINHEIRO, M. A. A Logística reversa: o caso da destinação de pneus inservíveis no Brasil. In: ENCONTRO INTERNACIONAL SOBRE GESTÃO EM PRESARIAL E MEIO AMBIENTE (ENGEMA), 12, 2010, São Paulo. Anais do XII ENGEMA. São Paulo: ENGEMA, 2010.

BAUER, J. M. et al. Destinação de pneus usados servíveis e inservíveis: do is estudos de caso. REGET, v. 19, n. 2, p. 1292-1302, 2015.

BERNARDO, M.; LIMA, R. S. Planejamento e implantação de um programa de coleta seletiva: utilização de um sistema de informação geográfica na elaboração das rotas. Revista Brasileira de Gestão Urbana, v. 9, n. suppl 1, p. 385-395, 2017.

BRASIL. Lei no. 12.305 de 02 de agosto de 2010. Institui a Política Nacional dos Resíduos Sólidos e dá outras providências. 2010. Disponível em: https://www.planalto.gov.br/ccivil_03/_ato2007-

2010/2010/lei//12305.htm. Acesso em: 27 fev. 2017.

CONAMA. Resolução no. 416 de 30 de setembro de 2009. Dispõe sobre a prevenção à degradação ambiental causada por pneus inservíveis e dá outras providências. 2009. Disponível em: http://www.mma.gov.br/port/conama/legiabre.cfm?codlegi=616. Acesso em: 27 fev. 2017.

CONAMA. Resolução n.․ 258, de 26 de agosto de 1999. Considera que os pneumáticos inservíveis abandonados ou dispostos inadequadamente constituem passivo ambiental e dá outras providências. 1999. Disponível em: http://www.mma.gov.br/port/conama/res/res99/res25899.html. Acesso em 27 de fev. 2017.

CORRÊA, J . A. J.; COSTA, A. C. L.; PEREIRA, I. C. N. Associação entre a precipitação pluvio métrica e a incidência de dengue em sete municípios do Estado do Pará. Revista Brasileira de Geografia Física, v. 9, n. 7, p. 2264 $2276,2016$.

COUTO, M. C. L.; LANGE, L. C. Análise dos sistemas de logística reversa no Brasil. Engenharia Sanitária e Ambiental, v. 22, n. 5, p. 889-898, 2017.

DEMAJ OROVIC, J.; AUGUSTO, E. E. F.; SOUZA, M. T. S. Logística reversa de REEE em países em desenvolvimento: desafios e perspectivas para o modelo brasileiro. Ambiente \& Sociedade, São Paulo, v. 19, n. 2, p. 119-138, abr./jun. 2016.

DENATRAN. Frota de veículos 2018. [2018]. Disponível em: http://www.denatran.gov.br/estatistica/237frota-veiculos. Acesso em: 08 jun. 2018.

DHOUIB, D. An extension of MACBETH method for a fuzzy environment to analyze alternatives in reverse logistics for automobile tire wastes, Omega, v. 42, n. 1, p. 25-32, 2014.

EHARA, M. et al. Addressing maladaptive coping strategies of local communities to changes in ecosystem servisse provisions using the DPSIR framework. Ecological Economics, v. 149, p. 226-238, 2018.

FAGUNDES, L. D.; AMORIM, E. S.; LIMA, R. S. Action Research in Reverse Logistics for End-Of-Life Tire Recycling, Systemic Practice and Action Research, v. 30, n. 5, p. 553-568, 2017.

FAUSTINO, O. W. C.; LEITE, E. F. Desenvolvimento sustentável e o fenômeno do empreendedorismo com pneus inservíveis: um estudo de caso na "pneu verde". Holos, Natal, v. 30, n. 5, p. 344-360, 2014.

FLORIANI, M. A.; FURLANETTO, V. C.; SEHNEM, S. Descarte sustentável de pneus inservíveis. Navus, Florianópolis, v. 6, n. 2, p. 37-51, abr./jun. 2016.

FONSECA, E. C. C. et al. Proposta de mapa de processos de logística reversa de pós-consumo sob a ótica da política nacional de resíduos sólidos. GEPROS, v. 12, n. 1, p. 83-89, 2017.

GOBBI, N. C. et al. Management of plastic wastes at Brazilian ports and diagnosis of their generation, Marine Pollution Bulletin, v. 124, n. 1, p. 67-73, 2017. 
GODOY, M. R. B. Dificuldades para aplicar a Lei da Política Nacional dos Resíduos Sólidos no Brasil. Caderno da Geografia, Belo Horizonte, v. 23, n. 39, p. 1-12, 2013.

GOVINDAN, K.; BOUZON, M. From a literature review to a multi-perspective framework for reverse logistics barriers and drivers, Journal of Cleaner Production, v. 187, p. 318-337, 2018.

GUIMARÃES, M. F. R. et al. Indicadores ambientais para o estudo da erosão marginal no Rio São Francisco. Caminhos da Geografia, Uberlândia, v. 11, n. 34, p. 84-92, jun. 2010.

HOORNWEG, D.; BHADA-TATA, P.; KENNEDY, C. Environment: Waste production must peak this century. Nature, v. 502, n. 7473, p. 615-617, 2013.

IBAMA. Relatório de Pneumáticos 2017. [2017]. Disponível em: http://ibama.gov.br/phocadownload/pneus/relatoriopneumaticos/ibama-relatorio-pneumaticos-2017.pdf Acesso em: 27 fev. 2017.

IBÁÑEZ-FORÉS, V. et al. Influence of implementing selective collection on municipal waste management systems in developing countries: A Brazilian case study. Resources, Conservation and Recycling, v. 134, p. 100-111, 2018.

IBGE. Instituto Brasileiro de Geografia e Estatística. Censo 2010. Rio de Janeiro: IBGE; 2010. Disponível em: http://censo2010.ibge.gov.br/resultados.html. Acesso em: 09 set. 2017.

IBGE. Instituto Brasileiro de Geografia e Estatística. Estimativas da população residente no Brasil. Rio de J aneiro: IBGE; 2017. Disponível em: https://www.ibge.gov.br/estatisticas-novoportal/sociais/populacao/9103estimativas-de-populacao.html. Acesso em: 09 jun. 2018.

LAGARINHOS, C. A. F. Reciclagem de pneus: análise do impacto da legislação ambiental através da logística reversa. 2011. 291 p. Tese (Doutorado em Engenharia) - Escola Politécnica da Universidade de São Paulo, São Paulo, 2011.

LAGARINHOS, C. A. F.; TENÓRIO, J. A. S. Logística reversa dos pneus usados no Brasil. Polímeros: Ciência e Tecnologia, São Carlos, v. 23, n. 1, p. 49-58, 2013.

LEITE, P. R. Logística reversa: meio ambiente e competitividade. São Paulo: Saraiva, 2017.

LEWISON, R. L. et al. How the DPSIR framework can be used for structuring problems and facilitating empirical research in coastal systems. Environmental Science \& Policy, v. 56, p. 110-119, 2016.

LIMA, V. M.; COSTA, S. M. F.; RIBEIRO, H. Uma contribuição da metodologia Peir para o estudo de uma pequena cidade na Amazônia: Ponta de Pedras, Pará. Saúde e Sociedade, São Paulo, v. 26, n. 4, p. 1071-1086, 2017.

LIU, X. et al. Evaluating the sustainability of marine industrial parks based on the DPSIR framew ork. J ournal of Cleaner Production, v. 188, p. 150-170, 2018.

LUZ, L.; DURANTE, D. A guerra dos pneus: a controvérsia entre Brasil e Comunidades Europeias so bre 0 comércio internacional de pneus usados. Desenvolvimento e Meio Ambiente, v. 27, p. 37-55, jan./jun. 2013.

MALEKMOHAMMADI, B.; JAHANISHAKIB, F. Vulnerability assessment of wetland land scape ecosystem services using driver-pressure-state-impact-response (DPSIR) model. Ecological Indicators, v. 82, p. 293-303, 2017.

MOREIRA, I. F.; GUARNIERI, P. Preferência dos consumidores por empresas que implementam práticas de logística reversa como meio de fidelização: estudo na indústria de cosméticos brasileira, Revista Gestão Industrial, v. 12, n. 4, p. 171-192, 2016. 
PEDRAM, A. et al. Integrated forward and reverse supply chain: a tire case study. Waste Management, v. 60, p. 460-470, 2017.

PERIM, T. M. P. et al. Correlações entre transporte e desenvolvimento econômico aplicadas ao turismo: uma análise a partir do município de Caldas Novas/Go - Brasil. Revista Gestão e Planejamento, Salvador, v. 18, p. 256-272, 2017.

PRODANOV, C. C.; FREITAS, E. C. de. Metodologia do trabalho científico: métodos e técnicas da pesquisa e do trabalho acadêmico. 2. ed. Novo Hamburgo: Universidade Feevale, 2013.

PNUMA. Metodologia para a elaboração de relatórios GEO Cidades. Manual de aplicação. México: PNUMA, 2001.

PUPPHACHAI, U.; ZUIDEMA, C. Sustainability indicators: a tool to generate learning and adaptation in sustainable urban development. Ecological Indicators, v. 72, p. 784-793, 2017.

RAMOS-QUINTANA, F. et al. Quantitative-qualitative assessments of environmental causal networks to support the DPSIR framework in the decision-making process. Environmental Impact Assessment Review, v. 69, p. 42-60, 2018.

RECICLANIP. Reciclanip: o ciclo sustentável do pneu. [2017]. Disponível em: http://www.reciclanip.org.br. Acesso em: 13 mar. 2017.

RLEC. What is Reverse Logistics?. [2017]. Disponível em: http://www.rlec.org/glossary.html. Acesso em: 14 set. 2017.

RODRIGUES, S. M.; AOKI, M.; OLIVER, F. C. Diagnóstico situacional de pessoas com deficiência acompanhadas em terapia ocupacional em uma unidade básica de saúde. Cadernos de Terapia Ocupacional da UFSCar, v. 23, n. 4, p. 781-794, 2015.

ROGERS, D. S.; TIBBEN-LEMBKE, R. Going backwards: reverse logistics trends and prac-tices. Reno, NV: Reverse Logistics Executive Council, 1998.

SARMIN, N.S. et al. The DPSIR framework for causes analysis of mangrove deforestation in Johor, Malaysia. Environmental Nanotechnology, Monitoring \& Management, v. 6, p. 214-218, 2016.

SCHNEIDER, D. D. et al. Indicadores para serviços de abastecimento de água e esgotamento sanitário voltados às populações vulneráveis. Revista Brasileira de Ciências Ambientais, n. 17, p. 65-76, set. 2010.

SILVA, C.S.S.L.; KOOPMANS, F.F.; DAHER, D.V. O Diagnóstico situacional como ferramenta para o planejamento de ações na Atenção Primária a Saúde. Revista Pró-UniverSUS, v. 7, n. 2, p. 30-33, 2016.

SILVA, S. S. F. et al. Indicador de sustentabilidade pressão - estado - impacto - resposta no diagnóstico do cenário sócio ambiental resultante dos resíduos sólidos urbanos em Cuité, PB. REUNIR, v. 2, n. 3, p. 76-93, 2012.

SOUZA, C. D. R.; D'AGOSTO, M. A. Análise dos custos logísticos aplicada à cadeia logística reversa do pneu inservível. Revista Transportes, Rio de Janeiro, v. 21, n.2, 2013.

SPERANZA, L. G.; MORETTI, R. S. Logística reversa: análise de processos implementados. Oculum ensaios, Campinas, v. 11, n. 2, p. 287-299, 2014.

VERMA, P.; RAGHUBANSHI, A. S. Urban sustainability indicators: challenges and opportunities. Ecological Indicators, v. 93, p. 282-291, 2018. 